\title{
O ciberjornalismo à luz da complexidade do informacionalismo
}

\author{
Patrícia Pinheiro Almeida \\ Universidades do Porto e de Aveiro \\ patvitara@gmail.com \\ Fernando Zamith \\ Universidade do Porto \\ zamith@gmail.com
}

\begin{abstract}
Resumo
O processo de transformação dos indivíduos para a atual sociedade em rede instigou o crescente sistema complexo presente neste novo século. A necessidade de compartilhamento e a criação de códigos culturais passaram a depender da capacidade tecnológica das sociedades, direcionando a informação ao jornalismo na rede, mais especificamente ao ciberjornalismo. Este que, pela sua evolução pós convergência digital, busca uma conexão sólida de discurso entre a complexidade do meio e a informação, levando, assim, a uma organização global através da tecnologia.
\end{abstract}

Palavras-chave: Paradigma tecnológico, paradigma da complexidade, ciberjornalismo, sociedade em rede, discurso.

\begin{abstract}
The process of transformation of individuals for the current network society instigated the growing complex system present in this new century. The need for sharing and creation of cultural codes came to depend on the technological capacity of societies, directing the information to the media on the network, more specifically to online journalism. This, by its evolution post digital convergence, seeks a solid connection pitch between the complexity of the environment and information, thus leading to a global organization through technology.
\end{abstract}

Keywords: Technological paradigm, the paradigm of complexity, online journalism, the network society, speech. 


\section{O processo de transformação do conhecimento}

A complexidade é desafio e não a solução

Edgar Morin

Mais do que a evolução no sentido de melhoria, como defendiam os pensadores do século XIX, a transformação - como conceito de alteração na forma, o que não necessariamente remete à melhoria - tem sido um processo cada vez mais constante e significativo no desenvolvimento humano. A partir da metade para o final do século $X X$, principalmente após as grandes revoluções tecnológicas informacionais e seu enorme fluxo de interação, esse processo de transformação sofreu uma notável mudança estrutural. Essa mudança tem ocasionado uma complexidade social que oscila entre a ordem e a desordem, segundo o sociólogo Edgar Morin (1977), onde é preciso opor e ligar esses dois movimentos, pois a ideia de interação, que une os elementos, e a de transformação, que pode organizar ou dispersar os mesmos, são, ao mesmo tempo, complementares, competitivas e opostas, formando uma simbiose de duas lógicas, sendo esta a dialógica ${ }^{5}$ da complexidade.

A noção de complexidade - um termo que deriva do latim complexus, que, por sua vez, significa aquilo que é tecido junto, em rede - é preconizado por Morin (1995) como um paradigma de mundo menos formatado em modelos que se creem explicativos e solucionadores. Para ele, a base da complexidade não é o fato de que a essência do mundo é complexa, mas que esta essência é sim inconcebíbel, tornando-se fundamental um exercício de um pensamento complexo para uma melhor compreensão do mundo.

O sistema em que vivemos constantemente constitui novas formas, sendo que, na concepção dessas novas formas por meio da interação entre as partes, cada uma dessas partes sofre um processo de transformação, gerando uma ideia de organização, fecundada da união das interações e transformações. Quanto mais informação ${ }^{6}$ se adquire, mais o ser humano desconsidera outras ou assimila estas para elaborar a sua visão organizada sobre determinado assunto.

Tal conjunto de transformações em busca de uma forma de organização da informação está diretamente ligado à troca de conhecimento. Porém, para que ocorra a ideia de organização, é necessário que as partes interajam em busca de um objetivo comum: a construção do todo, sem negar o outro e sem considerar única e absoluta sua verdade, evitando um comportamento etnocêntrico, em que o indivíduo considera as suas normas e valores culturais superiores aos das outras culturas. Morin indica que é preciso considerar a questão do contexto pertencente a cada uma das partes, sendo inevitável e imprescindível que a construção do conhecimento aconteça de maneira interdisciplinar. Reside, assim, a

$5 \mathrm{Na}$ linguística, a dialógica foi definida por Mikhail Bakhtin como toda comunicação verbal, de qualquer tipo que seja. Ele define o dialogismo como sendo um processo de interação entre o locutor e o locutário, a partir da noção de recepção e compreensão de uma enunciação.

6 A origem etimológica da palavra "informação" provém do latim informatio, que tem o sentido de "dar forma de uma ideia de algo a alguém". Em um sentido mais amplo, caracteriza-se como um "conjunto estruturado de representações mentais e emocionais codificadas." (Silva, 2006, p. 150). 
complexidade por meio do confrontamento destes diferentes contextos em que tanto os indivíduos quanto a organização passam por um processo de transformação.

No desenvolvimento informacional, científico e tecnológico da sociedade, essa troca de conhecimento tem na comunicação a principal ferramenta de multiplicação, compartilhamento e memorização da informação, exteriorizando, assim, uma das funções do cérebro humano, a memória - ideia defendida por Yves-François Le Coadic (1994), apontando que essas operações de multiplicação e memorização explicam uma boa parte do que se costumou chamar de explosão da informação (mais exatamente explosão da quantidade de informações), uma das fontes geradoras da complexidade social. Memória esta que Jacques Derrida (2001) apresenta como uma parte da consciência do ser humano em constante mutação pelo "desejo absoluto" da mesma que, nos dias atuais, representa o contraponto à tentativa do homem de diminuir, ao mesmo tempo, o incessante ritmo de processamento de informações devido a essa nova realidade informacional.

Com a inserção das novas tecnologias no contexto social, principalmente após a introdução de ferramentas que permitem o compartilhamento de informações cada vez mais intenso e acelerado, a construção do conhecimento tem sofrido mutações nas últimas décadas, incitando mais um processo de transformação estrutural da sociedade, bem como a emergência de um novo paradigma tecnológico no qual "[...] a tecnologia é condição necessária mas não suficiente para a emergência de uma nova forma de organização social baseada em redes, ou seja, na difusão de redes em todos os aspectos da actividade na base das redes de comunicação digital" (Castells, 2005, p. 17).

Esse novo paradigma, baseado nas Tecnologias de Informação e Comunicação (TICs), impulsiona a sociedade a "se apoderar" da tecnologia, segundo Castells (2005), fazendo com que a própria evolução tecnológica seja influenciada pela maneira como as pessoas usam suas ferramentas. Aqui implica a coexistência de uma influência mútua: a sociedade influencia a tecnologia, como também a tecnologia influencia a sociedade.

\section{Um adendo ao "paradigma"}

A palavra "paradigma" tem origem no grego paradeigma, significando modelo ou padrão, o que corresponde a algo que vai servir de exemplo a ser seguido. No âmbito filosófico, o paradigma relaciona-se com questões epistemológicas, a exemplo dos filósofos da natureza, que remetem o paradigma a um modelo referente ao mundo exemplar das ideias. Sua presença destaca-se, contudo, a partir do final do século XIX, na linguística, por meio da teoria do signo de Ferdinand de Saussure, em que ele se referia a uma relação entre o signo e o conjunto de elementos que constituem a língua.

O estudo dos signos vem atrelado ao surgimento do homem que, ansioso por entender e interpretar-se a si mesmo e ao mundo, desenvolveu formas de estudar os signos e seus significados/sinais. Na Antiguidade grega, havia a filosofia do signo por meio do 
desenvolvimento de uma teoria do conhecimento humano. Por exemplo, no campo da medicina, o diagnóstico médico era descrito como um processo de semêiosis, o que não era ainda considerada a teoria geral dos signos, apenas uma parte dela. Na Idade Média, desenvolveu-se um tipo elaborado de "doutrina dos signos". O termo empregado era repraesentatio que, a princípio, era indicado como a relação entre imagem e som original, em que os signos (stare pro - estar no lugar de) estão no lugar das coisas que os causam e daquelas a que eles se remetem (Boulnois, 1999). No século XVII, o britânico John Locke, no Ensaio sobre o entendimento humano, definiu a semeiotiké como uma das principais áreas dos estudos do conhecimento humano.

Seguindo a sua tradição da semeiotiké, dois séculos após, Charles Peirce tornou-se um dos principais estudiosos do tema. Ele definiu a semiótica como sendo a ciência que tem por objeto de investigação todas as linguagens possíveis e qualquer fenômeno de produção de significação e de sentido, tornando-se a Teoria Geral dos Signos. A Semiótica de Peirce estuda o contexto dos signos por meio de uma Tríade [R - Representamen / O - Objeto / I Interpretante]. Já Saussure abordou a teoria dos signos a partir da semiologia, que foi definida como uma ciência da comunicação humana sobre o estudo da "vida dos signos como parte da vida social", abordando fenômenos translinguísticos (textuais) e códigos culturais.

$\mathrm{Na}$ teoria dos signos de Saussure, existe uma relação binária entre um significante (o material que significa/faz significado, a forma sonora e/ou escrita) e um significado (o conceito, a ideia mental, o conteúdo semântico). Desse modo, se todo signo representa alguma coisa, no caso do paradigma, este poderia ser tomado como um signo (símbolo), resultando daí o significado, sendo ele a imagem mental da noção do paradigma na mente do receptor. Contudo, essa noção de paradigma como um significante resultante de um significado poderia ser incapaz de remeter a um fundamento concreto nas coisas, dependendo da interpretação de quem dá significado a elas, podendo ser o paradigma tomado como um signo impreciso.

No século XX, anterior a Morin e Castells, o físico Thomas Kuhn deu vários significados ao termo paradigma, destacando-se a definição de que "paradigmas são as realizações científicas universalmente reconhecidas que, durante algum tempo, fornecem problemas e soluções modelares para uma comunidade de praticantes de uma ciência" (Kuhn, 1991, p. 13). Para o autor, as ciências evoluem através dos paradigmas. Se um paradigma apresenta problemas e possibilidades de solução no campo científico, a transição de paradigmas corresponde a uma crise que dá vasão para a sua mudança por meio de uma revolução científica. Nas palavras de Morin, no que se refere à sociedade informacional, essa transição seria o processo de transformação complexo em que é preciso opor e ligar ordem e desordem para haver uma simbiose da informação e, assim, formar um novo conhecimento organizado. 


\section{O paradigma informacional}

A emergência de um novo processo de transformação estrutural da sociedade contemporânea, anunciado por Castells e o paradigma tecnológico, tem no informacionalismo o princípio organizador da sociedade em rede e sua dependência do fluxo informacional que é criado por elas, possibilitado pelas Tecnologias de Informação e Comunicação (TICs). Os efeitos da disseminação da informação pelas TICs, que correspondem a uma revolução de paradigma com a criação das chamadas redes, impulsionadas pelo desenvolvimento das tecnologias principalmente a partir da década de 1990, são tratadas por Castells como "[...] estruturas abertas capazes de expandir de forma ilimitada, integrando novos nós desde que consigam comunicar-se dentro da rede, ou seja, desde que compartilhem os mesmos códigos de comunicação" (Castells, 1999, p. 498). Esses códigos de comunicação se apresentam como uma forma renovadora do capitalismo moderno por meio da produção e circulação de produtos e também como uma maneira de buscar eliminar as diferenças, pois as redes têm, a princípio, uma organização menos hierárquica e centralizadora. No informacionalismo, as TICs passam a ser os elementos primordiais de domínios da vida social e econômica por meio da capacidade de geração de riqueza e criação de códigos culturais, que dependem da capacidade tecnológica da sociedade e dos indivíduos.

O que é específico do modo informacional de desenvolvimento é a ação do conhecimento sobre o conhecimento como fonte principal da produtividade. [...] $O$ tratamento da informação visa aperfeiçoar a tecnologia do tratamento da informação como fonte de produtividade, num círculo virtuoso de interação entre os conhecimentos que estão na base da tecnologia e a aplicação da tecnologia, afim de melhorar a geração do conhecimento e o tratamento da informação [...]. (Castells, 1999, p. 41-42)

Esse novo paradigma é caracterizado por abrangentes processos e contextos comunicacionais tornados possíveis pelas revoluções de ferramentas eletrônicas e tecnológicas, onde existe um aumento da capacidade humana para processar e comunicar, que Castells nomeia como "informacional-comunicacionalismo eletrónico", tornando o paradigma ainda mais abrangente por afetar toda a atividade humana.

\section{A comunicação na rede}

O princípio da sociedade em rede - apontado por Castells como um processo de transformação paradigmático associado às relações entre a globalização ${ }^{7}$, a economia e as novas TICs - possibilita uma cultura social multimensional, com uma comunicação mais plural.

\footnotetext{
7 A globalização é um processo de integração econômica, cultural, social e política, que diz respeito à forma como os países interagem e aproximam pessoas. Foi gerada pela necessidade capitalísta de formar uma aldeia global, abrindo para a possibilidade de conquista de novos mercados. Apresentou traços iniciais no período mercantilista entre o século XV e XVIII, iniciou o seu desenvolvimento a partir da Revolução Industrial e intensificou-se após a Segunda Guerra Mundial. Porém, com a aceleração do desenvolvimento de novas tecnologias de informação e de comunicação, houve um maior movimento a datar da década de 1970, ganhando velocidade nos anos 80 até ao momento.
} 
Essa cultura é, sobretudo, global, vigente em uma nova estrutura informacional abrangente, com um poder de disseminação e dominação que opera segundo da inclusão/exclusão. As redes integram e excluem, funcionando como pontos de conexão e de transformação interativa de fluxos sociais.

Nesse espaço multimensional em rede, a comunicação é inserida no centro da estruturação social, exprimindo uma transformação cultural paradigmática nas sociedades e nos indivíduos, imputada, principalmente, pela capacidade de dominação. Segundo Castells, essa dialética entre dominação e autonomia no funcionamento comunicacional-informacional está, por vezes, centralizada nos meios de comunicação jornalísticos, sendo estes atores privilegiados no novo contexto tecnológico da sociedade em rede. "La cultura común de la 'sociedad red global' es una cultura de protocolos que permite la comunicación entre diferentes culturas sobre la base no necesariamente de valores compartidos, sino de compartir el valor de la comunicación" (Castells, 2009, p. 67).

Assim, a nova cultura não está baseada no conteúdo, mas no processo, no protocolo, evidenciada por Castells como uma cultura global da "comunicação pela comunicação", em que há um excesso de proliferação de informação, não necessariamente conhecimentos. E esse apontamento corrobora o pensamento de Edgar Morin sobre a complexidade da informação (cada vez mais fragmentada) enquanto conhecimento, este que somente sobe um degrau na escala da transformação social quando, enquanto organização, relaciona-se com as informações e insere-se no contexto destas.

\section{A integração da informação no ciberespaço}

Com as transformações tecnológicas do século XX e a globalização, a crescente busca por informações, a necessidade de compartilhamento rápido ou instantâneo e de forma democrática fez com que os meios midiáticos se adaptassem, direcionando a informação ao jornalismo na rede, mais especificamente ao ciberjornalismo, uma "especialidade do jornalismo que emprega o ciberespaço para investigar, produzir e, sobretudo, difundir conteúdos jornalísticos" (Salaverría, 2005a, p. 21). Este que, por ser um meio de ferrramentas hipertextuais $^{8}$ - foi do plano linear e bidimensional para o tridimensional e com uma nova

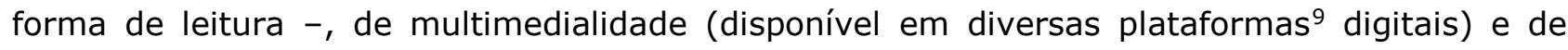
interatividade, conexão entre a fonte, o jornalismo e o público de forma interativa e com participação dos leitores. Com isso, o ciberjonalismo visava ser parte integrante do informacionalismo digital, uma conexão sólida entre a complexidade do meio e a informação, levando, assim, a uma organização global através da tecnologia.

8 Com a possibilidade do hipertexto na rede a partir do final do século $X X$, o texto passa a ser explorado de forma mais ágil e simples. Essa nova ferramenta na internet, através de suas hiperligações, permite que o leitor elabore, com uma simples conexão, sua própria estratégia de leitura, percorrendo o caminho que achar mais conveniente. Essa conexão não linear é denominada hiperlink, ou simplesmente link (ligação em inglês).

9 A plataforma é um ambiente em que se permite ter um conjunto de medias em torno delas, tendo um conjunto de códigos (sons, letras, dígitos) que estabelece um parâmetro de comunicação e informação. (Cavalcanti; Nepomuceno, 2007) 
As primeiras argumentações sobre convergência digital (fusão de tecnologias e conteúdo em uma única plataforma) começaram a surgir no final dos anos 70 . Nicholas Negroponte (1979), por exemplo, já discorria sobre a digitalização e suas consequências na programação e integração de texto e áudio. Porém, foi no início deste século XXI, com a intensificação da convergência digital mediática completa (transferência de conteúdo de jornal, rádio, TV e internet ${ }^{10}$ para uma única plataforma) - em especial após a intensificação do uso de dispositivos móveis - e com maior participação do leitor/espectador/usuário neste processo, que o tema ganhou maior projeção.

Essa modalidade de disponibilização de conteúdos, imputada pela convergência digital mediática ${ }^{11}$, tem encontrado no jornalismo um dos principais canais de integração virtual dos meios, onde velhos e novos formatos se unificam, reconfigurando a relação entre a media e o seu público. Salaverría e Negredo (2008) assim referem a convergência digital:

[...] processo multidimensional, que, facilitado pela implantação generalizada das tecnologias digitais de telecomunicação afeta o âmbito tecnológico, empresarial, profissional e editorial das empresas de media, propiciando a integração de espaços, métodos de trabalho e linguagens anteriormente desagregados, de forma que os jornalistas elaboram conteúdos distribuídos através de múltiplas plataformas, mediante as linguagens próprias de cada uma. (Salaverría; Negredo, 2008, p. 45)

Destaca-se que no início desse processo, os primeiros veículos jornalísticos tradicionais limitavam-se a apenas transpor para a internet os conteúdos dos jornais, rádios e televisões, na íntegra, ação identificada como "shovelware" (mera transposição de conteúdos do meio tradicional para a Internet). No entanto, os veículos de comunicação jornalística tradicionais perceberam que a internet é um meio com características singulares, sendo "merecedor de uma atenção especial e de linguagens diferentes, e, simultaneamente, potenciador de uma fragmentação da produção e do consumo nunca antes vista, que poderia resultar numa rutura com a clássica relação de poder topdown a que os mass media estavam habituados e da qual, porventura, não quereriam abdicar" (Zamith, 2013, p. 19).

O fato de haver uma maior participação do leitor/espectador/usuário na produção e também no compartilhamento de conteúdo informacional, fez com que o território midiático deixasse de ser dominado apenas por jornalistas. Desse modo:

[...] a antiga audiência (o público, o cidadão comum, os antigos recetores de notícias) começou a abandonar o seu papel de mero agente passivo e a participar neste

\footnotetext{
10 A internet foi idealizada nos Estados Unidos em 1969, a princípio para uso militar, e se estendeu às pequenas faculdades e empresas, até chegar às residências a partir do final da década de 1980. A rapidez de distribuição se tornou determinante para o crescimento exponencial da informação na rede, agilidade relacionada aos elementos: interatividade, tecnologia do hipertexto, multimédia, digitalização, computação e informação distribuídas, compartilhamento e cooperação - que caracterizam a internet como sistema até então único de geração, armazenamento e disseminação, proliferando, assim, novas fontes de informação.

11 No jornalismo, a convergência digital ocorre quando há transferência de conteúdos de diversas medias (jornal, rádio, TV, celular e internet) para um único ambiente virtual, onde é possibilitado ao usuário receber informações integradas, com facilidade de migrar de uma media a outra de forma não linear.
} 
complexo processo de pesquisa, produção e difusão de informação/notícias, através de fóruns, caixas de comentários, sites pessoais e coletivos, weblogs, microblogs, wikis, redes sociais e outras ferramentas de expressão, ação, interação, escolha, partilha, recomendação e participação acessíveis a qualquer pessoa que entre na grande rede ubíqua que é a Internet. (Zamith, 2013, p. 20)

Outro estudioso com pensamento análogo, no tocante de que a palavra 'convergência' consegue definir transformações tecnológicas em conjunto com as culturais e sociais, é Henry Jenkins (2009). Para ele, insere-se ainda, nesse processo, as transformações mercadológicas. Conforme o autor, o conjunto dessas transformações se dá por três fatores: a transposição de conteúdos de múltiplas plataformas de media, a integração e compartilhamento entre os mercados midiáticos e o comportamento migratório dos públicos consumidores de informações comunicacionais - destacando este último. Em um século em que novos modelos digitais permitem adaptações e atualizações de informações, o usuário é estimulado a participar de um processo de transformação ${ }^{12}$ cultural informacional acelerada e complexa.

Outra fase da convergência tecnológica na media foi marcada pela inserção do hipertexto na rede, a partir de 1995, ocasião em que os links alcançaram o ápice. Daniela Bertocchi (2007, p. 134-137) destaca dois eixos do conceito de hipertexto: "associação" e "conexão". A "associação" no sentido de que o hipertexto trabalha mais por associação do que por indexação, abolindo a linguagem linear e apresentando um conteúdo que não está limitado pela estrutura e pela organização. Já a "conexão" é identificada no hipertexto como forma de arquivo documental eletrônico, em que formam uma rede de informações textuais organizadas de "um modo complexo, não linear, para facilitar a exploração rápida de grandes corpos de conhecimento; ou seja, trata-se de uma base de dados hipertextual que apresenta uma interface para permitir ao utilizador navegar por tal base, passar pelos links desejados, explorando novas áreas de interesse; exige a presença simultânea de três elementos: nós (unidades semânticas), associações conectando entre nós (hiperligações) e uma interface interativa". Para Zamith,

No ciberjornalismo, é mais habitual vermos o hipertexto assumir uma função de conexão, dada a prevalência de estruturas hipertextuais axiais, mas também é possível encontrá-lo no sentido de associação, designadamente nas reportagens hipermédia feitas em estrutura reticular. (Zamith, 2013, p.9)

O hipertexto na web é um exemplo da transformação do modo de construir o conhecimento. É a busca por uma nova forma de adaptação do texto por meio da realidade tecnológica. A transição do jornalismo impresso para o digital por meio do processo

12 Mais do que a evolução (no sentido de melhoria, ideia defendida por pensadores do século XIX), a transformação como conceito de alteração na forma, não necessariamente de melhoria - tem sido um processo constante e significativo no desenvolvimento humano no decorrer de sua caminhada. O homem vive em constante processo de transformação ligado à troca de conhecimento, considerado por Norbert Elias (1993) como processo civilizador. 
convergente também causa alterações na apresentação e nas características da notícia ${ }^{13}$ (sempre em busca de suportes mais estáveis), na forma de transmissão e na própria presença da media na sociedade. Atualmente, com público consumidor da notícia assumindo um papel de receptor, multiplicador e agente participativo da produção da informação, este interage de acordo com um novo conjunto de regras que, segundo Jenkins (2006), nenhum de nós entende por completo. $E$ as regras integram esse contexto informacional em que a ordem e desordem, citadas por Morin, configuram a complexidade atual de uma sociedade que se prepara para transpor mais um processo de tranformação.

\section{O discurso, o texto e o contexto no ciberjornalismo}

Posto o cenário atual em que a sociedade está a "se apoderar" da tecnologia (esta que consequentemente influencia a sociedade), o ciberjornalismo - por ser diferenciado de outros tipos do jornalismo devido à sua funcionalidade tecnológica operacional e pela utilização de ferramentas hipertextuais no ciberespaço - carece de estudos que discutam a complexidade discursiva da notícia no ciberespaço. A complexidade se refere a um contexto informacional envolto de ferramentas cada vez mais desenvolvidas em prol da informação e vice-versa.

Sendo uma construção social, o discurso jornalístico só pode ser analisado se consideramos o seu contexto histórico-social - além de suas condições de produção -, comparando e confrontando realidades, segundo Morin, e em busca de um processo de transformação, global e informacional da sociedade em rede, propagado por Castells. Desse modo, os jornalistas, agentes produtores e mediadores da notícia, estabelecem uma série de relações (com fontes, sociedade ou instituições) para cumprir suas funções, valendo-se de técnicas que definam, acentuam ou excluam determinados aspectos dos acontecimentos sociais.

Esse discurso, por meio da narrativa da notícia, remete aqui à prática social (conjunta, e não individual) de produção de textos, ao contrário dos padrões positivistas do jornalismo tradicional da construção da notícia individual, linear, baseada na pirâmide invertida e critérios determinados de objetividade do lead, dentre outros. Essas possibilidades narrativas integradas permitidas pela convergência digital multimédia "requerem, consequentemente, o planeamento das estórias através da elaboração de um guião (storyboard), encarado como essencial no processo de escrita não-linear. A aplicação do storyboarding no planeamento de uma estória online poderá, dependendo das práticas e exigências de cada media online, caber ao próprio jornalista" (Bastos, 2013, p. 5).

Mesmo se atendo a essas questões da narrativa positivista, os ciberjornalistas têm que

13 Notícia é a informação atual, verdadeira, carregada de interesse humano e capaz de despertar a atenção e a curiosidade de grande número de pessoas. Ela é a "matéria-prima do jornal, a base de tudo o que é publicado, da nota mais alegre ao mais sério editorial. Em sua busca concentra-se todo o esforço da redação. Ela comanda o ritmo de trabalho, determina horários, impõe gastos, provoca edições extra. Sem ela não haveria o que dizer, comentar, criticar ou elogiar." (Amaral, 1997, p. 39) 
estar atentos a contextos de leitores da web com perfis e exigências distintas, individuais e também coletivas, além dos modos de leitura, de navegação e de interação que se consolidam nos ambientes virtuais. A produção de notícias no contexto dos novos media deve considerar a totalidade das modalidades comunicacionais advindas da convergência digital midiática (texto, áudio, vídeo, gráficos, animação), para adequação do jornalista a essa nova realidade. "Não mais as notícias estão constrangidas pelas limitações técnicas dos média tradicionais, seja imprensa, televisão ou rádio. Em vez disso, todas as modalidades da comunicação humana estão disponíveis para contar as estórias da maneira mais interessante, interactiva, ondemand e personalizada possível" (Pavlik, 2001, p. 17).

Como moldura do texto, o contexto da notícia envolve elementos tanto da realidade do jornalista que escreve quanto a do receptor, resultando no significado compartilhado. As escolhas dos jornalistas são pautadas pela aparência que a 'realidade' assume, pelas convenções e rotinas que moldam a sua profissão e pelas instituições. Assim, o contexto da produção da notícia no ciberespaço vale-se da situação histórico-social de um texto como da inter-relação com outros textos por meio do hipertexto na rede, esta que Mikhail Bakhtin (1963) e Julia Kristeva (1974) apontaram como teoria da intertextualidade, em que enfatizam a interminável permutação de textualidades. Já Gerard Genette (1982) propôs um termo, segundo ele, mais inclusivo: a transtextualidade, tudo que coloca um texto em relação com outros textos por meio de hiperlinks, seja essa analogia manifesta ou secreta. Por exemplo, citações, referências ou informações subliminares.

A rotina e o processo da notícia jornalística se manifestam no texto, sendo a materialização do discurso ofertada para interpretação do público. Ao dialogar com a análise do discurso francesa, em que a leitura representa papel fundamental para o resultado de uma interpretação do discurso apresentado aos leitores, destaca-se o jornalismo como objeto deste texto e representante disseminador de leituras do mundo transformadas em discurso. "A leitura produzida pelo Jornalismo, portanto, pode ser (re)lida por meio de dispositivos que permitem adentrar nos sentidos e filiações que se estabelecem no dizer, materializado em texto (oral, escrito, etc)" (Schwaab, 2007).

$\mathrm{Na}$ construção do discurso no ciberespaço, o jornalismo traz todos os aspectos inseridos no texto e em seu contexto para trabalhar a compreensão do discurso para criar e disseminar seus significados (conscientes ou além do texto) que, na análise do discurso, possuem relações complexas, mudando as palavras de sentido conforme a intepretação de quem as emprega. Para Umberto Eco (2012), as interpretações do mundo e dos textos são baseadas na individualização da relação de simpatia (similaridades) que ligam os dois, sendo, desse modo, necessário realizar um critério interpretativo, que o autor nominou como "semiótica hermética".

A imagem, o conceito, a verdade descoberta sob o véu da semelhança, será vista, por sua vez, com um signo de outra transferência analógica. Toda vez que a pessoa acha 
que descobriu uma similaridade, esta sugere outra similaridade, numa secessão interminável. Num universo dominado pela lógica da similaridade (e da simpatia cósmica), o intérprete tem o direito e o dever de suspeitar que aquilo que acreditava ser o significado de um signo seja de fato o signo de um outro significado. (Eco, 2012, p. 53)

Todas as interpretações do discurso do texto jornalístico são relevantes para a construção dos sentidos. No procedimento de análise é necessário remeter os textos ao discurso e estabelecer as relações entre eles, considerando as variáves interpretações de leitura. Porém, para Eco, "depois que o mecanismo da analogia se põe em movimento não há garantia de que vai parar".

Para facilitar a maneira como o público irá ter acesso a essa informação no futuro, o discurso no ciberjornalismo vem ao encontro da complexidade apontada por Morin no que diz respeito à busca de uma informação organizada, equilibrada, onde Castells apresenta a solução ao proferir que o Informacionalismo é o princípio organizador dessa troca de ordem e desordem informacional. Para que aconteça a troca de informações, o ciberjornalismo necessita de tecnologias cada vez mais avançadas, fazendo com que o conhecimento seja transmitido de forma igual e em tempo real para todos.

O texto e o contexto no ciberjornalismo são primordiais, pois só existirá entendimento/compreensão entre as partes que buscam a organização, que a tecnologia conecta, se ambas escreverem e compreenderem o mesmo código. Não se pode, por exemplo, passar uma informação em linguagem extremamente técnica para um leitor comum de contexto variado pois, para ele, de nada significaria o discurso utilizado, pois sua compreensão seria quase nula. Concluindo então que ambas as partes querem o mesmo objetivo, buscando a ordem, de nada vale o informacionalismo se o ciberjornalismo não adaptar seu discurso narrativo a fim de fazer a conexão entra as partes. É preciso ter noções que viabilizem uma reflexão complexa, inserindo o jornalismo nesse amplo ambiente contemporâneo das manifestações textuais.

Com a ação comunicativa integrada e a convergência digital midiática, a linguagem textual está sendo alterada constantemente, adaptando-se aos tipos de informação e/ou notícia. O discurso do ciberjornalismo deve preceder a um processo de transformação social, buscando mudar, se adaptar, inovar, transpondo o ambiente do ciberspaço.

\section{Considerações finais}

A sociedade do século XXI vive uma profunda dicotomia econômica e cultural. A tecnologia da informação tornou-se ferramenta indispensável à efetivação do processo de reestruturação socioeconômica. De um lado, pensamentos indivualizados de uma sociedade informacional na qual a representação do eu (principalmente nas redes sociais virtuais) utiliza ferramentas e plataformas tecnológicas para proveito próprio, e de outro, essa mesma sociedade buscando criar códigos culturais, unido-se em prol de causas sociais variadas (além 
de uma integração comercial oriunda de um capitalismo globalizado) para integrar essa nova "sociedade em rede". Uma sociedade em que valores individuais transcendem os coletivos, mas que ao mesmo tempo a busca pelo coletivo se destaca. A interação entre esses processos e as reações por eles desencadeadas inserem-se no obscuro paradigma complexo e transformativo preconizado por Morin.

Todo esse processo de ordem e desordem individual e social busca o equilíbrio para ascender à organização. A interação que une os elementos pode trazer a transformação social que, por sua vez, pode trazer a ordem e a desordem, já que a transformação pode ser tanto positiva quanto negativa. E a organização plena dessa sociedade em rede só acontecerá - e se acontecer - caso haja um consenso de objetivos comuns, havendo troca de conhecimento e de informações. O indivíduo não pode se prender à verdade absoluta etnocêntrica. É preciso considerar as suas normas e seus valores culturais, mas a compreensão do ponto de vista do outro é primordial para alcançar a organização. A sociedade não pode ser vista como um bloco, e sim, como uma teia. Precisamos encarar cada pessoa individualmente, depois em sociedade, como uma teia conectada. Não se pode criar grupos e isolados: deve haver comunicação entre esses grupos.

Baseando-nos no conceito de Castells (1999) de que o informacionalismo é o "princípio organizador" da sociedade em rede e sua dependência do fluxo informacional que é criado por elas, possibilitado pelas Tecnologias de Informação e Comunicação (TICs), conectamos aqui esses dois autores. Já que Morin buscava a organização (o equilíbrio), Castells deu a solução dizendo que o informacionalismo é o princípio organizador. Dessa forma, é preciso usar a tecnologia para que aconteça a troca de conhecimento de forma igual e em tempo real (online) com todos os indivíduos, para que assim ambas as partes busquem um objetivo em comum, trazendo a organização plena, pretendida por Morin. Para que aconteça a ordem entre os indivíduos comuns, ampliando para a ordem entre indivíduos diferentes, tem que haver troca de informações através da tecnologia de forma igual e ao mesmo tempo para todos.

Dentro desse contexto, o ciberjornalismo surge como sendo uma possibilidade de busca por informação e compartilhamento que faz a interação, em tempo real e de forma igual, da sociedade em rede. Ciberjornalismo significa continuidade, face à periodicidade da imprensa, rádio e TV; e ainda integralidade, interatividade, versatilidade e multiplicidade. Segundo Castells (1999), em O paradigma da tecnologia da informação, uma das características dessa revolução tecnológica é a convergência de tecnologias específicas para um sistema altamente integrado, no qual trajetórias tecnológicas antigas ficam impossíveis de se distinguir. Assim, o ciberjornalismo adapta-se, a cada momento, às plataformas constantemente atualizadas, e em um formato convergente, em que ferramentas hipertextuais se integram no mundo de possibilidade informacionais integradas.

A partir do Paradigma da Complexidade de Edgar Morin, aponta-se que, no atual momento de eclosão de uma pluralidade de formas narrativas, precisamos de resgatar 
conceitos mais abrangentes, noções que viabilizem uma reflexão complexa, inserindo o jornalismo nesse amplo ambiente contemporâneo das manifestações textuais. Dentro do processo de convergência digital do meios, características como a hipertextualidade, multimedia e interatividade apontam para um paradigma de discurso complexo, em que é preciso pensar a organização das informações no todo e no contexto.

\section{Referências bibliográficas}

Amaral, Luiz. Técnica de jornal e periódico. Rio de Janeiro/Brasília: T. Brasileiro, 1978.

Bakhtin, Mikhail. Estética da criação verbal. São Paulo: Martins Fontes, 2000.

Bastos, Helder. Ciberjornalismo: dos primórdios ao impasse. Porto: Universidade do Porto, 2013. Artigo. In: http://www.bocc.ubi.pt/pag/bastos-helder-ciberjornalismo-dos-primordiosao-impasse.pdf

Bertocchi, Daniela. A Narrativa Jornalística no Ciberespaço: transformações, conceitos e questões. Tese de mestrado. Universidade do Minho, 2007. In: http://bertocchi.info/tese/MestradoDanielaBertocchi_divulgacao 2007.pdf

Boulnois, Olivier. Être et représentation. Paris: Presses Universitaires de France, 1999.

Canavilhas, João Messias. Webjornalismo: considerações gerais sobre jornalismo na web. Beira Interior: BOCC, 2001. In: http://www.bocc.ubi.pt/pag/_texto.php3?html2=canavilhasjoaowebjornal.html

Castells, Manuel. A sociedade em rede. $8^{a}$ ed. São Paulo: Paz e Terra, 1999.

1999. A era da informação: economia, sociedade e cultura. Rio de Janeiro: Paz e Terra, ; Cardoso, Gustavo. A sociedade em rede: do conhecimento à ação política. Conferência. Belém: Imprensa Nacional, 2005. Comunicación y poder. Madrid: Alianza Editorial, 2009.

Cavalcanti, Marcos; Nepomuceno, Carlos. O conhecimento em rede: como implantar projetos de inteligência coletiva. Rio de Janeiro: Elsevier, 2007.

Coadic, Yves-François Le. A ciência da informação. 3a ed. Brasília: Ed. Gomes. 1994.

Derrida, Jacques. Mal de Arquivo: uma impressão freudiana. $1^{a}$ edição. Tradução Cláudia de Moraes Rego. Editora Relume. Rio de Janeiro. 2001.

Eco, Umberto. De Gutenberg à Internet. Florianópolis: Centro Tecnológico UFSC, 2003. In: http://www.inf.ufsc.br/ jbosco/InternetPort.html Interpretação e Superinterpretação. São Paulo: Ed. Wmf Martins Fontes, 2012.

Elias, Norbert. O processo civilizador. Rio de Janeiro: Jorge Zahar Editora, 1993.

Genette, Gerard. Palimpsestes: la littérature au second degré. Paris: Éditions du Seuil, 1982.

Jenkins, Henry. Cultura da convergência. São Paulo: Aleph, 2009. Cultura da Conexão. São Paulo: Aleph, 2014.

Kristeva, Julia. Introdução à Semanálise. São Paulo: Perspectiva, 1974. 
Kuhn, Thomas. A estrutura das revoluções científicas. São Paulo: Perspectiva, 1991.

Morin, Edgar. A cabeça bem feita: repensar a reforma, reformar o pensamento. Rio de Janeiro: Bertrand Brasil, 2003.

O método 1: da natureza da natureza. $2^{\mathrm{a}}$ ed. Porto Alegre: Sulina, 1977.

Negroponte, Nicholas. Being Digital. New York: Vintage Books, 1995.

Pavlik, John. Journalism and New Media. New York: Columbia University Press, 2001.

Peirce, Charles S. Semiótica. Tradução J. Teixeira Coelho Neto. São Paulo: Perspectiva, 1999.

Pelegrini, Djalma. Sobre o conceito de paradigma no pensamento de Edgar Morin. Uberaba: Revista Triângulo, $2012 . \quad$ In: http://www.uftm.edu.br/revistaeletronica/index.php/revistatriangulo/article/view/178_

Salaverría, Ramón; Negredo, Samuel. Periodismo integrado: convergencia de medio y reorganización de redacciones. Barcelona: Sol90 Media, 2008.

Salaverría, Ramón. De la pirámide invertida al hipertexto. Navarra: Atic, 2001. In: http://unav.es/fcom/mmlb/mmlab/investig/piram.htm . Redacción Periodística en Internet. Barcelona: Eunsa, 2005a. (coord.) Cibermedios. Sevilla: Ed. Comunicación Social, 2005b.

Santos, Helena. Desafios paradigmáticos e globais no campo das Ciências da Informação e Comunicação: em busca de novas fundamentações. Porto: CETAC.media, 2012.

Sausurre, Ferdinad de. Curso de lingüística geral. São Paulo: Cultrix, 1991.

Schwaab, Regis. Para ler de perto o jornalismo. Porto Alegre: Em Questão, 2007. In: http://seer.ufrgs.br/index.php/EmQuestao/article/view/2002/1324

Silva, Armando Malheiro da. A Informação: da compreensão do fenómeno e construção do objecto científico. Porto: Ed. Afrontamento, 2006.

Silva, Juremir Machado da. (Org.) Edgar Morin: as duas globalizações. Joaquim Clotet: complexidade e comunicação, uma pedagogia do presente. Porto Alegre: Ed. Sulina, 2007.

Traquina, Nelson. Teorias do jornalismo. 2a ed. Florianópolis: Insular, 2005.

Zamith, Fernando. A contextualização no ciberjornalismo. Porto: Edições Afrontamento/CETAC.MEDIA, 2013.

* Todos os sites acima citados foram acessados pela última em 10/12/2015. 